\title{
Effect of Hardening Induced by Cold Expansion on Damage Fatigue Accumulation and Life Assessment of Aluminum Alloy 6082 T6
}

\author{
Bendouba Mostefa ${ }^{\mathrm{a}}$, Aid Abdelkrim ${ }^{\mathrm{a} *}$, Benhamena Ali ${ }^{\mathrm{a}}$, Benguediab Mohamed \\ a Laboratoire $L P Q 3 M, B P$ 305, Université de Mascara, Algérie \\ ${ }^{\mathrm{b}}$ Département de Génie Mécanique, Université de Sidi-Bel-Abbès, Algérie
}

Received: October 2, 2011; Revised: July 13, 2012

\begin{abstract}
Hole cold expansion (HCE) is an effective method to extend the fatigue life of mechanical structures. During cold expansion process compressive residual stresses around the expanded hole are generated. The enhancement of fatigue life and the crack initiation and growth behavior of a holed specimen were investigated by using the 6082 Aluminum alloy. The present study suggests a simple technical method for enhancement of fatigue life by a cold expansion hole of pre-cracked specimen. Fatigue damage accumulation of cold expanded hole in aluminum alloy which is widely used in transportation and in aeronautics was analyzed. Experimental tests were carried out using pre-cracked SENT specimens. Tests were performed in two and four block loading under constant amplitude. These tests were performed by using two and four blocks under uniaxial constant amplitude loading. The increasing and decreasing loading were carried. The experimental results were compared to the damage calculated by the Miner's rule and a new simple fatigue damage indicator. This comparison shows that the 'damaged stress model', which takes into account the loading history, yields a good estimation according to the experimental results. Moreover, the error is minimized in comparison to the Miner's model.
\end{abstract}

Keywords: aluminum alloys, cold expansion, compressive residual stress, hardening, block loading, fatigue damage, fatigue life enhancement

\section{Introduction}

Over the last 25 years the cold expansion process has been commonly used to improve the fatigue life of components containing fastener holes ${ }^{1}$. Cold expansion is employed usually in components which are exposed only to service conditions at ambient temperature. The cold-worked process introduces beneficial residual circumferential stresses into an annular region around the hole, and the presence of this compressive residual stress inhibits the growth and propagation of $\mathrm{cracks}^{1,2}$.

In order to increase the service life of components some methods have been developed. One of these methods, which was used in this study, is to form a controlled compressive residual stress field around the hole ${ }^{3,4}$. However, the improvement in fatigue life is difficult to quantify. The residual stresses resulting from the cold expansion process are not uniform through the thickness 5 .

Earlier work on cold expansion has used both analytical and numerical two-dimensional models to predict residual stress $^{6}$. Furthermore, combining the residual stress distribution with a fatigue crack growth rate calculation is difficult due to the three-dimensional nature of the problem and complicating phenomena such as crack closure 7 . McNeil and Heston reported that depending upon the fatigue stress level; the process can result in an improvement in fatigue life by a factor of 3 to $10^{8-10}$.

$\mathrm{In}^{11-14}$, the authors show the sensitivity of the degree of expansion. In a first phase the residual life increases but beyond a critical value of remaining life decreases sharply and growth is extremely detrimental.

*e-mail: aid_abdelkrim@yahoo.com
In service conditions, the components or structures are subjected to random or variable block loading. Different relationships ${ }^{11}$ have been proposed to calculate the effect of variable amplitude loading conditions. However, these procedures need the identification of many parameters. In literature, in the particular case of block loading, the analysis for this phenomenon is oriented only to two loading steps.

Miner's rule ${ }^{15}$ is very much used to evaluate the fatigue damage accumulation when the components or structures are subjected to variable block loading. In this work, the results of a study on fatigue damage accumulation of cold expanded hole in aluminum alloys subjected to block loading are presented.

Tests were carried out using pre-cracked SENT specimens and inserting an expanded hole at the crack tip. The degree of the cold expansion was chosen equal to $4.3 \%$. Tests were performed in two and four block loading under constant amplitude.

The experimental results were compared to the damage calculated by the Miner's rule and a new simple fatigue damage indicator ${ }^{16-19}$.

\section{General Principle of the Method}

In this study, cold expansion is achieved by inserting an oversized rigid ball from one side (entry face) of the holed plate and removing it from the other side (exit face). The degree of cold expansion DCE is defined by the relation: 


$$
D C E \%=\frac{(D-d)}{d} \times 100 \%
$$

where $\mathrm{d}$ is the diameter of the hole drilling and D is the diameter of the rigid ball. Different technique can be used to repair a cracked component. The cold working expansion process was realized by forcing a hard steel ball of $6 \mathrm{~mm}$ inside a predrilled hole (the initial diameters of the hole are: 5.9, 5.8, 5.75, 5.6 and $5.5 \mathrm{~mm}$ for aluminum alloy and 5.8, 5.75 for steel) (Figure 1).

The singularity due to the crack can be removed by drilling.

A cold expansion of the hole introduces compressive residual stresses that are beneficial in terms of lifetime until a critical degree of expansion where it becomes not beneficial for structures. Both aspects are illustrated in Figures 2 and $3^{[17,20]}$.

The geometry effect on the residual stresses distribution at the crack tip was study little. The bibliography treats primarily the case of the closed cavities and not the case of the open cavities. Both phenomenons are illustrated in Figure 4.

\section{Experimental Procedure}

\subsection{Materials and specimens}

The material used for this study was aluminum alloy Al 6082 T6, with chemical composition (wt. (\%)), $0.6 \mathrm{Mg}$, $0.7 \mathrm{Si}, 0.24 \mathrm{Fe}, 0.06 \mathrm{Cu}, 0.9 \mathrm{Mn}, 0.02 \mathrm{Cr}, 0.06 \mathrm{Zn}, 0.02$ $\mathrm{Ti}$ and balance $\mathrm{Al}$. We see that the main alloying elements of this alloy are magnesium and silicon. Some of the mechanical properties are given in Table 1 .

A difference gap of $10 \%$ between the characteristics of the uncracked specimens and the batch of specimens with hole was noticed.

\subsection{Cold expansion process}

The specimens used for this investigation were conforms to ASTM standards ${ }^{22}$. The geometry of the fatigue test specimen cut in the longitudinal direction is shown in Figure 5.

For getting specimens with an expanded hole of $6 \mathrm{~mm}$ in diameter we drilled a hole of $\varnothing 5.75 \mathrm{~mm}$ at the pre-crack tip and then a cold-working expansion process was conducted by forcing a steel ball of $6 \mathrm{~mm}$ diameter. The fatigue tests were carried out using a $100 \mathrm{kN}$ capacity Instron hydraulic machine. The loading frequency was $30 \mathrm{~Hz}$ and a stress ratio $\mathrm{R}$ of 0.57 . During fatigue testing, a video camera with scale of $0.1 \mathrm{~mm}$ was used to determine the crack initiation in the entry and exit faces of specimen.

\subsection{Experimental technique}

The stress intensity factor amplitude is determined by the following relation ${ }^{23}$ :

$$
\Delta K=\frac{\Delta P}{B \sqrt{W}} \cdot f\left(\frac{a}{W}\right)
$$

$\Delta \mathrm{P}$, loading amplitude; $\mathrm{f}(\mathrm{a} / \mathrm{W})$, calibration function; a, crack length; $\mathrm{W}$, width; $\mathrm{B}$, thickness.

The calibration function $\mathrm{f}(\mathrm{a} / \mathrm{W})$ is determined by the following relation ${ }^{21}$ :
$f\left(\frac{a}{W}\right)=1.99\left(\frac{a}{W}\right)^{0.5}-0.41\left(\frac{a}{W}\right)^{1.5}+$
$18.7\left(\frac{a}{W}\right)^{2.5}-38.85\left(\frac{a}{W}\right)^{3.5}+53.85\left(\frac{a}{W}\right)^{4.5}$

In this configuration, the stress amplitude at the notch tip is approximated by the following expression ${ }^{23}$.

$\Delta \sigma=\frac{2 \Delta K_{\rho}}{\sqrt{\pi \rho}}$

where $\Delta K \rho$ is the stress intensity factor and $\rho$ is the radius of hole.

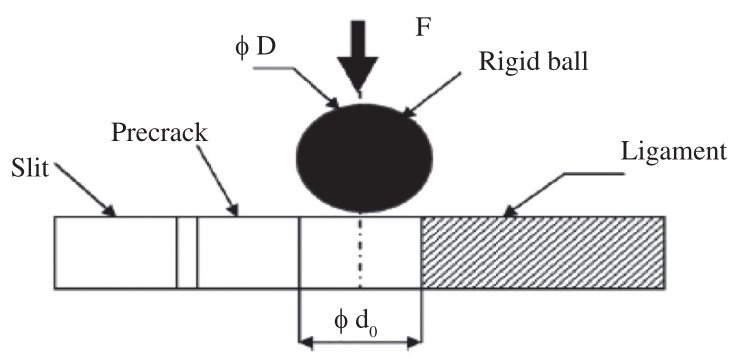

Figure 1. Cold expansion process.

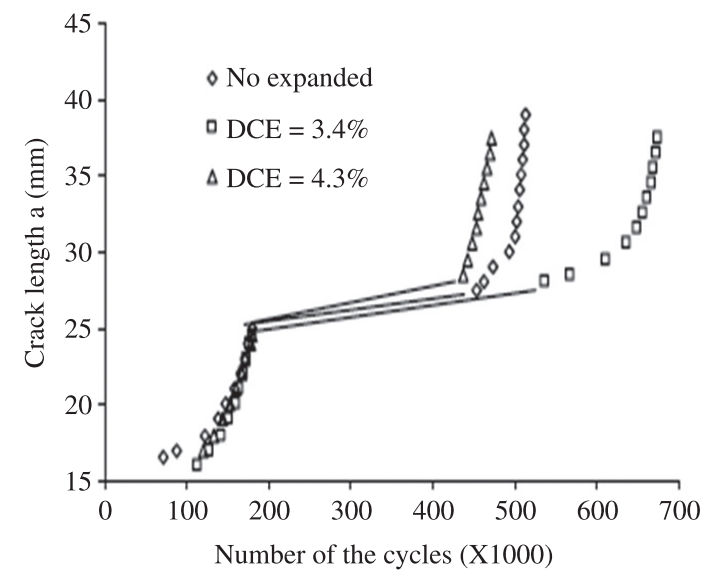

Figure 2. The curve of crack initiation according to the numbers of the cycles.

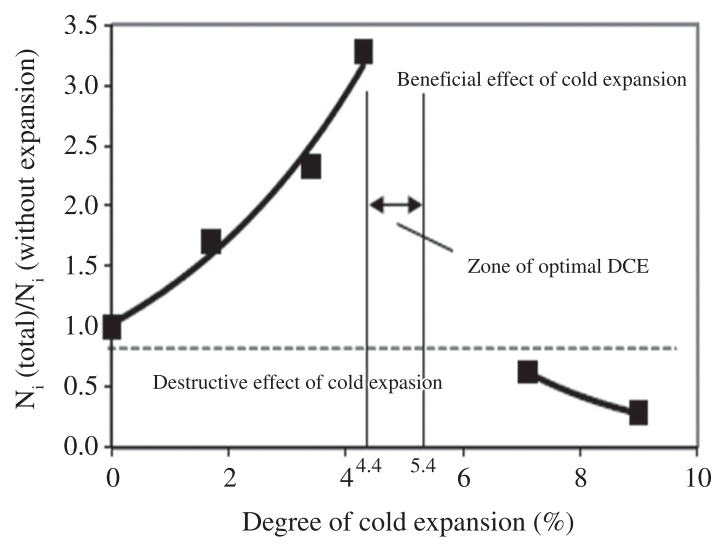

Figure 3. Normalized lifetime vs. DCE for aluminum alloy 6082. 


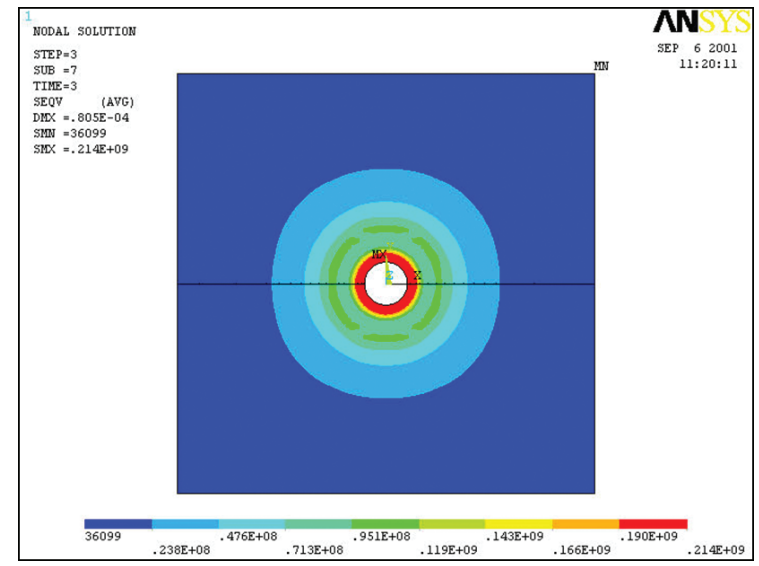

(a) Closed cavity

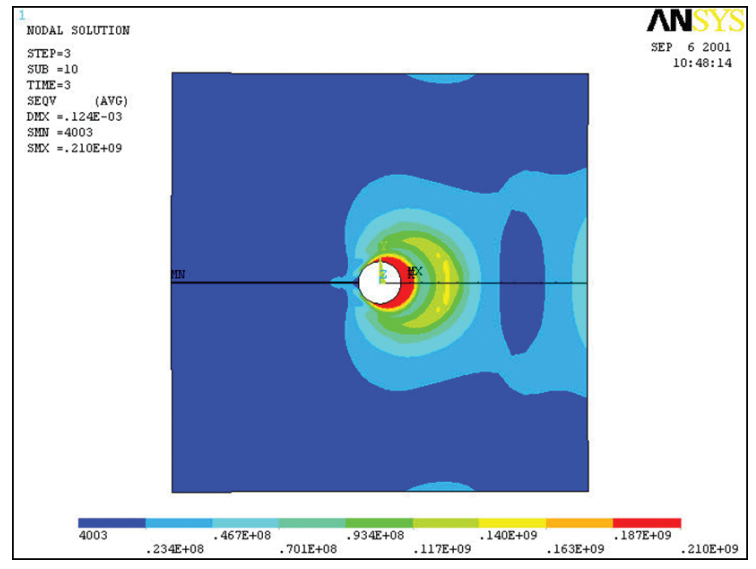

(b) Open cavity (crack)

Figure 4. The Von Mises stress distribution around a closed cavity and the open cavity ${ }^{21}$.

Table 1. Mechanical properties of the aluminum alloy.

\begin{tabular}{lcc}
\hline & & Numerical values \\
\hline Yield stress & $(\mathrm{MPa})$ & 280 \\
Ultimate tensile strength & $(\mathrm{MPa})$ & 327 \\
Strength coefficient & $\mathrm{K}(\mathrm{MPa})$ & 447 \\
Strain hardening exponent & $\mathrm{n}$ & 0.095 \\
Young's modulus & $(\mathrm{GPa})$ & 68 \\
Percent elongation & $\mathrm{A}(\%)$ & 12 \\
Hardness & $\mathrm{Hv} 50$ & 95 \\
\hline
\end{tabular}

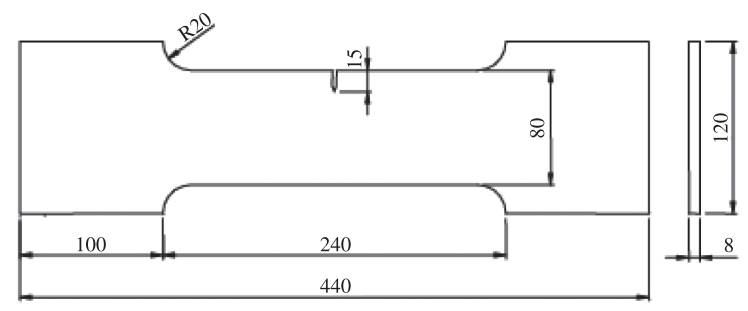

Figure 5. Geometry and dimensions of the fatigue test specimen.

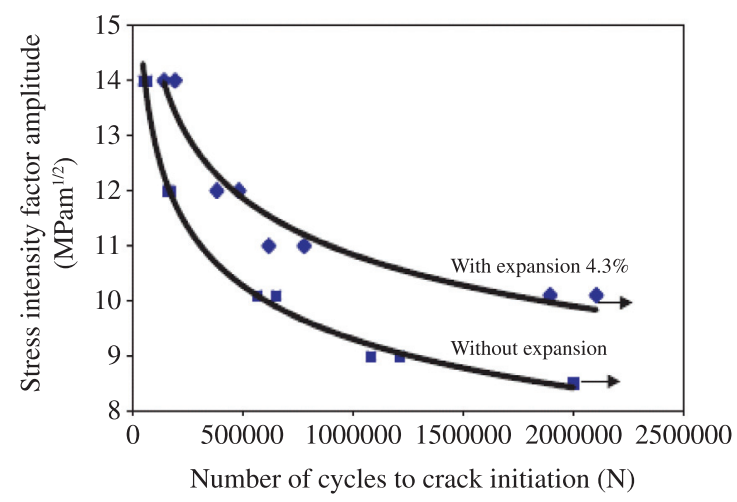

Figure 6. Fatigue endurance curve $(\mathrm{R}=0.57)$.
Table 2. Experimental conditions.

\begin{tabular}{lll}
\hline Block number & $\boldsymbol{\Delta} \mathbf{K}\left(\mathbf{M P a} \mathbf{~ m}^{\mathbf{1 / 2}}\right)$ & Number of cycles At failure \\
\hline 1 & 11 & 856.000 \\
2 & 11.7 & 528.000 \\
3 & 12.4 & 336.000 \\
4 & 13.1 & 220.000 \\
\hline
\end{tabular}

Endurance curves are shown in Figure 6. These are based on constant amplitude test and the failure was considered at the crack initiation ${ }^{17}$.

\section{Results and Analysis}

The experimental conditions are given in Table 2. Eight tests were carried out for increasing loading conditions and as much for decreasing loading. To evaluate the effect between these loading conditions, the Miner's Rule was considered for damage accumulation.

Two and four cyclic stress levels were considered (Tables 3 and 4) and two different sequences were applied. The aim of this set of tests is to determine the influence of increasing or decreasing loading conditions on lifetime and to prove that the proposed model takes into account the history of blocks loading and the nonlinearity of the accumulated damage unlike the Miner's rule.

The Miner's Rule considers the fractional damage, $D_{i}=n_{i} / N_{i}$, where: $n_{i}$ is the number of cycles at particular stress level and $\mathrm{N}_{i}$ is the number of cycles to failure at particular stress level.

The total damage $\mathrm{D}=\Sigma \mathrm{n}_{\mathrm{i}} / \mathrm{N}_{\mathrm{i}}$ and the failure is assumed to occur when $\mathrm{D}=1$. The experimental results were compared to the damage calculated by the Miner's rule ${ }^{15}$ and a new simple fatigue damage indicator 'damaged stress model ${ }^{16-20}$. The results are given in Tables 5, 6 and illustrated in Figure 7. We compare the prediction of the both models, Miner's rule and damaged stress model, with the experimental results. 
Table 3. Experimental results for two blocks loading.

\begin{tabular}{llcccc}
\hline & & Specimen $\mathbf{N}^{\circ}$ & $\beta 1$ & $\beta 2$ & $\beta 1+\beta 2$ \\
\hline \multirow{2}{*}{ Increasing loading } & $\Delta \mathrm{K}_{1}=11$ & 1-2bexp. & 0.476 & $0.160^{\mathrm{a}}$ & 0.636 \\
& $\Delta \mathrm{K}_{2}=13.1$ & 2-2bexp. & 0.476 & $0.586^{\mathrm{a}}$ & 1.062 \\
& & 3-2bexp & 0.476 & $0.391^{\mathrm{a}}$ & 0.867 \\
\hline \multirow{3}{*}{ Decreasing loading } & $\Delta \mathrm{K}_{1}=13.1$ & 4-2bexp. & 0.452 & $0.073^{\mathrm{a}}$ & 0.525 \\
& $\Delta \mathrm{K}_{2}=11$ & 5-2bexp. & 0.452 & $0.116^{\mathrm{a}}$ & 0.568 \\
\hline
\end{tabular}

${ }^{a}$ crack initiation; $\beta \imath=n_{i} / N_{i}$.

Table 4. Experimental results for four blocks loading.

\begin{tabular}{clcccccc}
\hline & & Specimen $\mathbf{N}^{\circ}$ & $\beta \mathbf{1}$ & $\beta \mathbf{2}$ & $\beta \mathbf{3}$ & $\beta \mathbf{4}$ & $\beta \mathbf{1 +} \boldsymbol{\beta 2 + \beta 3 + \beta 4}$ \\
\hline \multirow{5}{*}{ Increasing loading } & $\Delta \mathrm{K}_{1}=11.0$ & 1-4bexp. & 0.238 & 0.235 & 0.233 & $0.316^{\mathrm{a}}$ & 1.022 \\
& $\Delta \mathrm{K}_{2}=11.7$ & 2-4bexp. & 0.238 & 0.235 & $0.186^{\mathrm{a}}$ & - & 0.659 \\
& $\Delta \mathrm{K}_{3}=12.4$ & 3-4bexp. & 0.238 & 0.235 & $0.168^{\mathrm{a}}$ & - & 0.641 \\
& $\Delta \mathrm{K}_{4}=13.1$ & 4-4bexp. & 0.238 & 0.235 & $0.214^{\mathrm{a}}$ & - & 0.687 \\
\hline \multirow{5}{*}{ Decreasing loading } & $\Delta \mathrm{K}_{1}=13.1$ & 5-4bexp. & 0.232 & $0.207^{\mathrm{a}}$ & - & - & 0.445 \\
& $\Delta \mathrm{K}_{2}=12.4$ & 6-4bexp. & 0.232 & $0.116^{\mathrm{a}}$ & - & - & 0.348 \\
& $\Delta \mathrm{K}_{3}=11.7$ & 7-4bexp. & 0.232 & 0.233 & $0.167^{\mathrm{a}}$ & - & 0.632 \\
& $\Delta \mathrm{K}_{4}=11.0$ & 8-4bexp. & 0.232 & 0.233 & 0.235 & $0.457^{\mathrm{a}}$ & 1.157 \\
& $\Delta \mathrm{K}_{5}=13.1$ & 9-4bexp. & 0.232 & 0.233 & $0.150^{\mathrm{a}}$ & - & 0.615 \\
& $\Delta \mathrm{K}_{6}=12.4$ & 10-4bexp. & 0.232 & 0.233 & $0.066^{\mathrm{a}}$ & - & 0.531 \\
\hline
\end{tabular}

${ }^{a}$ crack initiation; $\beta \mathrm{l}=\mathrm{n}_{\mathrm{i}} / \mathrm{N}_{\mathrm{i}}$.

Table 5. Damage accumulation for two blocks.

\begin{tabular}{cccc}
\hline Specimen $\mathbf{N}^{\circ}$ & $\begin{array}{c}\text { Miner } \\
\text { forecast }\end{array}$ & $\begin{array}{c}\text { Damaged } \\
\text { stress model }\end{array}$ & $\begin{array}{c}\text { Experiment } \\
\Sigma n / N\end{array}$ \\
\hline 1-2bexp. & 1.0 & 0.764 & 0.636 \\
2-2bexp. & 1.0 & 0.764 & 1.062 \\
3-2bexp. & 1.0 & 0.764 & 0.867 \\
\hline Mean Value & $\mathbf{1 . 0}$ & $\mathbf{0 . 7 6 4}$ & $\mathbf{0 . 8 5 5}$ \\
\hline 4-2bexp. & 1.0 & 0.585 & 0.525 \\
5-2bexp. & 1.0 & 0.585 & 0.568 \\
6-2bexp. & 1.0 & 0.585 & 0.625 \\
\hline Mean Value & $\mathbf{1 . 0}$ & $\mathbf{0 . 5 8 5}$ & $\mathbf{0 . 5 7 2}$ \\
\hline
\end{tabular}

Table 6. Damage accumulation for four blocks.

\begin{tabular}{cccc}
\hline Specimen $\mathbf{N}^{\circ}$ & $\begin{array}{c}\text { Miner } \\
\text { forecast }\end{array}$ & $\begin{array}{c}\text { Damaged } \\
\text { stress model }\end{array}$ & $\begin{array}{c}\text { Experiment } \\
\Sigma n / N\end{array}$ \\
\hline 1-4bexp. & 1.0 & 0.9 & 1.022 \\
2-4bexp. & 1.0 & 0.9 & 0.659 \\
3-4bexp. & 1.0 & 0.9 & 0.641 \\
4-4bexp. & 1.0 & 0.9 & 0.687 \\
5-4bexp. & 1.0 & 0.9 & 0.445 \\
Mean Value & $\mathbf{1 . 0}$ & $\mathbf{0 . 9}$ & $\mathbf{0 . 7 5 2}$ \\
6-4bexp. & 1.0 & 0.66 & 0.348 \\
7-4bexp. & 1.0 & 0.66 & 0.632 \\
8-4bexp. & 1.0 & 0.66 & 1.157 \\
9-4bexp. & 1.0 & 0.66 & 0.615 \\
10-4bexp. & 1.0 & 0.66 & 0.531 \\
Mean Value & $\mathbf{1 . 0}$ & $\mathbf{0 . 6 6}$ & $\mathbf{0 . 7 4 6}$ \\
\hline
\end{tabular}

Figure 7 shows the comparison between the models prediction and the experimental results for different loading modes (two and four blocks with increasing and decreasing loading) for a precracked specimens repaired by the cold expansion technique.

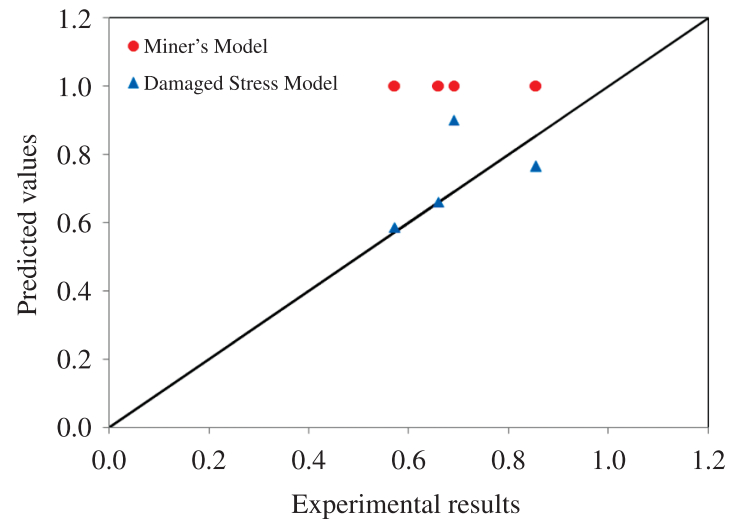

Figure 7. Comparison between theoretical results and experimental results for different loading conditions.

The figure confirms that the Damaged Stress Model predictions are in good agreement with the experimental results.

\section{Conclusion}

Fatigue damage accumulation in arresting crack holes with cold expansion process was studied. In total, 24 specimens were tested, eight specimens were used to obtain the fatigue endurance curve and 16 were subjected to increasing or decreasing blocks loading. Using the Miner's rule to calculate the cumulative life time we found that in both cases, increasing and decreasing blocks loading, the experimental results were below prediction. The results obtained by the model of the damage stress are compared with the experimental results and a good 
agreement has been found. The experimental results show that the load sequence has no significant effect on the crack reinitiating.

It seems that in the case of drilling with a cold expansion, the combination of the geometrical and mechanical effect attributed to the stress concentration factor associated with the compressive residual stresses predominate in the life time.

\section{References}

1. Lacarac VD, Smith DJ and Pavier MJ. The effect of cold expansion on fatigue crack growth from open holes at room and high temperature. International Journal of Fatigue. 2001; 23:S161-S170. http://dx.doi.org/10.1016/ S0142-1123(01)00125-6

2. Pasta S. Fatigue crack propagation from a cold-worked hole. Engineering Fracture Mechanics. 2007; 74:1525-1538. http:// dx.doi.org/10.1016/j.engfracmech.2006.08.006

3. Chandawanich $\mathrm{N}$ and Sharpe Junior WN. An experimental study of fatigue crack initiation and growth from coldworked holes. Engineering Fracture Mechanics. 1979; 11:609-620. http://dx.doi.org/10.1016/0013-7944(79)90122-X

4. Su X, Go M and Yan M. A simplified residual stress model for predicting fatigue crack growth behavior at coldworked fastener holes. Fatigue and Fracture of Engineering Materials and Structures. 1986; 9:57-64. http://dx.doi. org/10.1111/j.1460-2695.1986.tb01211.x

5. Pavier MJ, Poussard CGC and Smith DJ. A finite element simulation of the cold working process for fastener holes. Journal of Strain Analysis for Engineering Design. 1997; 32:287-300. http://dx.doi.org/10.1243/0309324971513418

6. Poussard C, Pavier MJ and Smith DJ. Analytical and finite element predictions of residual stresses in cold worked fastener holes. Journal of Strain Analysis for Engineering Design. 1995; 30:291-304. http://dx.doi. org/10.1243/03093247V304291

7. Lacarac VD, Garcia-Granada AA, Smith DJ and Pavier MJ. Prediction of the growth rate for fatigue cracks emanating from cold expanded holes. International Journal of Fatigue. 2004; 26:585-595. http://dx.doi.org/10.1016/j. ijfatigue.2003.10.015

8. McNeill WA and Heston AW. Coldworking fastener holes - theoretical analysis, methods of coldworking, experimental results. In: Proceedings of the ASM conference on residual stresses in design, process and materials selection; 1987; Cincinnati. Cincinnati; 1987.

9. Phillips JL. Sleeve coldworking fastener holes. Air Force Materials Laboratory, Wright-Patterson Air Force Base; 1974.

10. Ozedemir AT, Cook R and Edwards L. Residual stress distributions around cold expanded holes. In: Eighteenth ICAF symposium on estimation, enhancement and control of aircraft fatigue performance; 1995; Stockholm. Stockholm; 1995.

11. Bernard M, Bui-Quoc T and Burlat M. Effect of Recold Working on Fatigue Life Enhacement of a Fastener Hole. Fatigue and Fracture of Engineering Materials and Structures. 1995; 18(7-8):765-775. http://dx.doi. org/10.1111/j.1460-2695.1995.tb00902.x
In the other hand the load sequence has a minor effect. In this investigation, the compressive residual stresses at the edge of the hole are around of the yielding stress. The effective local applied stress is lower than the residual stress; this observation can explain the raison why there is no significant influence of the sequence loading. Currently, we achieve tests with more important loading in order to evaluate the sequence loading effect.

12. Pavier MJ, Pousard GC and Smith DJ. Effect of residual stress around cold worked holes on fracture under superimposed mechanical load. Engineering Fracture Mechanics. 1999; 63(6):751-773. http://dx.doi.org/10.1016/ S0013-7944(99)00050-8

13. Vulic N, Stjepan S and Grubisic V. Validation of Crack Arrest Technique by Numerical Modeling. International Journal of Fatigue. 1997; 19(4):283-291. http://dx.doi.org/10.1016/ S0142-1123(97)00008-X

14. Ghfiri R, Shi HJ, Guo R and Mesmacque G. Effect of Expanded and non expanded Hole on the Delay of Arresting Crack Propagation for Aluminum Alloys. Material Science and Engineering A. 2000; 286:244-249. http://dx.doi.org/10.1016/ S0921-5093(00)00805-4

15. Miner MA. Cumulative damage in fatigue. Journal of Applied Mechanics. 1945; 67:A159-A64.

16. Mesmacque G, Garcia S, Amrouche A. Sequential law in multiaxial fatigue: a new damage indicator. International Journal of Fatigue. 2005; 27(4):46:1-7.

17. Aid A. Cumul d'endommagement en fatigue multiaxiale sous sollicitations variables. [Thesis]. Algérie: Universitè de Sidi-Bel Abbes, 2006. p. 195. (in french).

18. Aid A, Semari Z, Amrouche A, Mesmacque G and Benguediab M. Non linear damage cumulative criterion on fatigue under random loading. Algerian Journal of Advanced Materials. 2006.

19. Aid A, Amrouche A, Bachir Bouiadjra B, Benguediab M and Mesmacque G. Fatigue life prediction under variable loading based on a new damage model. Materials \& Design. 2011; 32:183-191. http://dx.doi.org/10.1016/j.matdes.2010.06.010

20. Amrouche A, Su M, Aid A and Mesmacque G. Numerical study of the optimum degree of cold expansion: Application for the pre-cracked specimen with the expanded hole at the crack tip. Journal of materials processing technology. 2008; 197:250-254. http://dx.doi.org/10.1016/j.jmatprotec.2007.06.030

21. Garcia-Miranda JS. Développement d'un nouveau modèle d'endommagement et de cumul de dommage en fatigue sous sollicitations variables. [Thesis] France: University of Science and Technology of Lille; 2003. (in french).

22. American Society for Testing and Materials - ASTM. Designation E 647-88a: Standard test method for measurement of fatigue crack growth rates. ASTM; 1978.

23. Tanaka K, Nakai Y and Kawashima R. Fracture mecanics approach to fatigue crack initiation from deep notches. Engineering Fracture Mechanics. 1983;18(5):1011-23. http:// dx.doi.org/10.1016/0013-7944(83)90073-5 